\title{
REVISITANDO CHANDLER: o sistema de informações de custos também segue a estratégia?
}

\author{
Revisiting Chandler: does the cost information system also follow the strategy?
}

\author{
José Roberto Frega $^{[\mathrm{a}]}$, Iomara Scandelari Lemos ${ }^{[\mathrm{b}]}$, Alceu Souza ${ }^{[\mathrm{c}]}$, Heitor Takashi Kato $^{[\mathrm{d}]}$ \\ [a] Engenheiro Eletrônico, Doutor em Administração pela Pontifícia Universidade Católica do Paraná (PPAD/PUCPR), Curitiba, \\ PR - Brasil, e-mail: jose.frega@gmail.com \\ [b] Bacharel em Turismo, Doutoranda em Administração pela Pontifícia Universidade Católica do Paraná (PPAD/PUCPR), Curitiba, \\ PR - Brasil, e-mail: iomara.lemos@gmail.com \\ [c] Economista, prof. Dr. da Pontifícia Universidade Católica do Paraná (PPAD/PUCPR), Curitiba, PR - Brasil, e-mail: alceu.souza@ \\ pucpr.br \\ [d] Administrador, prof. Dr. da Pontifícia Universidade Católica do Paraná (PPAD/PUCPR), Curitiba, PR - Brasil, e-mail: heitor. \\ kato@pucpr.br
}

\section{Resumo}

Este artigo tem por objetivo mostrar, por meio de um estudo de caso, que a assertiva de Alfred Chandlera estrutura segue a estratégia - é abrangente o suficiente para incluir o sistema de informações de custos. Estuda-se o caso de uma indústria de tijolos e artefatos refratários situada no sul do Brasil e constata-se que, para atingir melhores níveis de competitividade, houve modificações no sistema de informações de custo para atender à estratégia selecionada. Num primeiro momento, a estrutura já existente limitou o leque de estratégias viáveis, e a empresa optou por adotar uma estratégia de diversificação com baixo custo. A nova estratégia induziu modificações na atual estrutura e também no sistema de informações de custos. Esse novo sistema - Custeio Direto na área gerencial e Activity Based Costing com direcionador tempo no setor produtivo - evidenciou informações sobre os produtos mais rentáveis e induziu a adoção de uma estratégia de diferenciação centrada nos produtos de maior margem. Conclui-se que a estrutura limitou a escolha da estratégia e essa, ao seu tempo, modificou a estrutura e reorientou a estratégia reiniciando o ciclo de alinhamento.

Palavras-chave: Alfred Chandler. Estratégia e estrutura. Gestão estratégica de custos.

\begin{abstract}
This paper aims to show, by means of a case study, that Alfred Chandler's assertion - the structure follows the strategy - is broad enough to include the cost information system. The case studied is that of a brick and refractory firm, located in southern Brazil. To achieve better competitiveness levels this firm provided modifications in the
\end{abstract}


cost information systems to comply with the chosen strategy. In a first moment, the existing structure limited the range of feasible strategies and the firm chose a diversification strategy with low cost. The new strategy induced modifications in the current structure and also in the cost information system. This new system - Direct Costing in the management area and time-driven Activity Based Costing in the production area - reveals the most profitable products and induced the firm to adopt a strategy of differentiation focused in the products with better margin. In conclusion, the assertion of Chandler is confirmed and also reveals that the structure has limited the choice of the strategies and that, on its turn, modified the structure and reoriented the strategy restarting, thus, the realignment cycle.

Keywords: Alfred Chandler. Strategy and structure. Strategic cost management.

\section{INTRODUÇÃO}

Na concepção de Guimarães (1982 apud ARAÚJO Jr., 1983, p. 70), a firma é uma unidade administrada por uma gerência central, que controla um pool de lucros e é responsável por sua aplicação, constituindo-se então em um locus de acumulação do capital. Implícita nesse conceito está a necessidade de obtenção de lucros e de uma estratégia para mantê-los ou aumentá-los. A compreensão do padrão de concorrência, a expectativa de crescimento da demanda, a capacidade de investimentos de expansão e a seleção da estratégia de competição influenciarão sobremaneira o processo de acumulação do capital. Assim, para Guimarães (1982 apud ARAÚJO Jr., 1983, p. 71), “o problema colocado para a firma consiste em encontrar aplicações para seus recursos, e se possível para os fundos externos que se pode obter, de modo a contribuir para o crescimento da firma e para o aumento de seus lucros". Essa linha de raciocínio é compatível com a posição de Penrose (1959 apud CARDOSO; BOMTEMPO; PINTO Jr., 2006, p. 71), na qual "o principal motivo para o crescimento das firmas pode ser explicado quando se assume que as decisões de investimentos são guiadas por oportunidades de aumentar a lucratividade".

As forças competitivas, ao serem mapeadas pela estratégia corporativa, implicam modificações de conduta e rearranjos estruturais para manter ou alcançar o patamar de rentabilidade desejado pela firma. A tendência natural é que a dinâmica das forças competitivas altere o posicionamento competitivo (pseudo-estado de equilíbrio), alterando-se a seguir a estratégia, que será o reflexo da adaptação da firma a essa avaliação ambiental. Segue-se à estratégia uma mudança de estrutura (CHANDLER, 2000).
Da mudança na estratégia e da disponibilidade de recursos financeiros decorrem decisões de investimentos para alinhar a estrutura à estratégia. Essa nova configuração induz a um novo ponto de equilíbrio da firma, levando o sistema a um novo estado ao fim de cada ciclo.

Dentre as maneiras de avaliar e perceber a orientação estratégica da organização pode-se enfatizar a análise de indicadores gerenciais operacionais e estratégicos. Grande parte desses indicadores é gerada a partir de uma base dados adequadamente construída. Se as informações resultam essencialmente operacionais e defasadas, o próprio conceito de estratégia, enquanto atuante ao longo de um grande espaço de tempo, fica prejudicado; por outro lado, se essas informações forem adequadamente geradas, de acordo com a necessidade da estratégia, sugere-se que há um alinhamento entre a estratégia e o sistema de informações. É oportuno enfatizar que as informações de custos constituem um módulo relevante desse sistema. Para Shank e Govindarajan (1997, p. 115), “o papel da informação contábil dentro de uma empresa é o de facilitar o desenvolvimento e a implementação das estratégias gerenciais". Para Souza e Clemente (2007, p. 14), o conceito de Gestão Estratégica de Custos se estabelece quando o sistema de informações é capaz de gerar informações sobre a capacidade de resposta da estrutura vis-à-vis a estratégia pretendida.

Este artigo tem por objetivo mostrar, por meio de um estudo de caso, que a assertiva de Alfred Chandler - a estrutura segue a estratégia - é abrangente o suficiente para incluir o sistema de informações de custos. Para tal, está organizado em cinco seções, incluindo esta introdução. A segunda seção trata da revisão teórico-empírica e se escora no trabalho clássico de Alfred Du Pont Chandler 
denominado Strategy and Structure, publicado em 1962, e é reforçada por contribuições de outros autores, como Porter; Barney; Day; Wernefelt; Guimarães; Souza e Clemente; Ghemawat; Shank e Govindarajan; Almeida et al.; Cardoso et al.; Cooper e Kaplan. A terceira seção apresenta os aspectos metodológicos da pesquisa, ressaltando a abordagem de estudo de caso. A quarta seção traz o estudo de caso propriamente dito, enfatizando as mudanças estratégicas e estruturais em decorrência da dinâmica das forças competitivas. A última seção trata das conclusões do estudo, destacando a abrangência da assertiva de Chandler, isto é, fica evidenciado que o sistema de informação de custo também se molda à estratégia.

\section{REVISÃO TEÓRICO-EMPÍRICA}

Esta etapa compreende uma revisão conceitual sobre visões de estratégia competitiva e seus reflexos nos sistemas de informações de custos na busca de vantagem competitiva.

\section{ESTRATÉGIA E VANTAGEM COMPETITIVA}

Poucas vantagens podem ser sustentadas indefinidamente, pois o tempo e a ação dos concorrentes as tornam obsoletas. Quanto mais dinâmico o ambiente, mais acelerado é o processo de criação e erosão de vantagens competitivas. Há uma relação causal intencional entre a formulação e a implementação da estratégia e a criação de vantagem competitiva. A intencionalidade está na criação de valor para a empresa (SOUZA; CLEMENTE, 2007, p. 6).

As numerosas definições de estratégias guardam similaridade entre si: um conjunto de objetivos e metas condicionados por fatores endógenos e exógenos à organização. Esses fatores podem ou não estar correlacionados com o conjunto de ações ativado pela estratégia selecionada. Tão importante quanto o conceito de estratégia é entender, no âmbito da competitividade empresarial, o seu objetivo. Há uma intencionalidade explícita na concepção da estratégia: criação de valor para a empresa, isto é, busca permanente de posicionamento competitivo que resultem em agregação de valor em longo prazo.

Para Porter (1998, p. 15), "uma estratégia corporativa de sucesso tem que nascer de uma estratégia competitiva e reforçá-la". Esse autor afirma também que o lema da estratégia competitiva é ser diferente e, para tanto, deve-se escolher de forma deliberada um conjunto diferente de atividades para proporcionar um mix único de valores. Porém, a estratégia também requer a compreensão da complexa trama da competição natural. As empresas podem combinar características, valores, serviços ou produtos diferentes de muitas maneiras, e sempre existirão várias possibilidades de coexistência competitiva, mas também muitas possibilidades para que cada competidor amplie o escopo de sua vantagem, mudando aquilo que o diferencia de seus rivais. Tendo-se em mente que o conceito de estratégia envolve um horizonte temporal, ou seja, uma linha de tempo ao longo da qual os eventos acontecem, não faz sentido olhar a estratégia por meio de um corte transversal do tempo, sem olhar os antecedentes e os sucedentes. Adicionalmente, Porter sustenta que a vantagem competitiva no mercado está em oferecer mais valor ao cliente por um custo equivalente (diferenciação) ou inferior (baixo custo). Complementando o conceito, Shank e Govindarajan (1997, p. 60-61) expõem que "[...] a análise da cadeia de valor é essencial para determinar exatamente onde, na cadeia do cliente, o valor pode ser aumentado e os custos reduzidos".

Ainda, segundo Porter, uma unidade empresarial pode desenvolver uma vantagem competitiva sustentável com base no custo ou na diferenciação, ou ambos. A liderança em custos pode ser obtida atuando-se em economias de escala na produção, usando-se um rígido controle de custos e os efeitos da curva de experiência, ou minimizando os custos em atividades que não agregam valor. Note-se que, em indústrias competitivas, enquanto o preço do produto é definido pelo mercado, os custos são determinados pelo processo de fabricação do produto. Assim, para criar valor, deve-se atuar duplamente: melhorar a percepção do consumidor a respeito da utilidade do produto, gerando uma maior disposição a pagar, e reduzir os custos, controlando e aprimorando o processo produtivo.

Wernerfelt (1984 apud CARDOSO; BOMTEMPO; PINTOJr., 2006,p. 71), com o intuito de "ampliar a visão de que a capacidade interna da 
empresa pode fazê-la alcançar um desempenho superior aos de seus concorrentes na indústria, propôs o que se denominou Visão Baseada em Recursos (VBR)". Tal pressuposto sugere que os recursos próprios e difíceis de copiar é que darão à firma uma vantagem competitiva e que garantirão uma rentabilidade acima da média. Segundo esses autores, essa abordagem contraria a posição de Porter de que a rentabilidade média da firma está condicionada à da indústria.

Barney (1991), seguindo o mesmo fio condutor, declara que uma firma possui vantagem competitiva quando implementa uma estratégia de criação de valor que não esteja sendo implementada por algum competidor, atual ou potencial, e que essa vantagem torna-se sustentável quando, em longo prazo, não é facilmente copiada ou imitada. De acordo com Porter (1985), a vantagem sustentável é avaliada simplesmente no decurso de prazo, ou seja, o horizonte de sustentabilidade é definido ad hoc. $\mathrm{Na}$ visão de Rumelt (1984 apud BARNEY, 1991) e de Lippman e Rumelt (1982 apud BARNEY, 1991), a vantagem competitiva é sustentável somente se ela continua existindo depois que os esforços para mantê-la cessaram. Para Day (1999), estratégia é buscar uma vantagem competitiva sobre os concorrentes e, simultaneamente, diminuir a erosão das vantagens atuais, isto é, prolongar o horizonte de sustentabilidade apregoado por Porter.

\section{ESTRATÉGIA E ESTRUTURA}

Alfred Chandler pode ser considerado

um dos fundadores da área da administração estratégica que não somente contribuiu para o desenvolvimento de dois conceitos fundamentais na área - estratégia e estrutura - como também para a compreensão dos mecanismos de crescimento da firma" (FLECK, 2003, p. 11-12, apud CARDOSO; BOMTEMPO; PINTO Jr., 2006, p. 70).

A base da assertiva de Alfred Chandler é uma pesquisa amplamente detalhada sobre as empresas nos Estados Unidos no período de 1850 a 1920. Suas principais obras são Estratégia e estrutura (1962), A mão visivel(1977), Escala e escopo (1990), Uma nação transformada pela informação (2000) e Inventando o século eletrônico (2002). Em Estratégia e estrutura, Chandler, contrariando a tendência de reestruturação de empresas, declara que a estrutura deve seguir a estratégia, tornando-se assim o primeiro teórico a defender a criação de um plano estratégico antes da elaboração de uma estrutura organizacional, ou seja, a estratégia deve preceder a estrutura. Em $A$ mão visivel ele se contrapõe a Adam Smith ao declarar que a revolução nos negócios americanos deve-se mais à gestão, aos gestores e às organizações do que à mão visível do mercado (ENCICLOPÉDIA TEMÁTICA, 2009). Em Escala e escopo, Chandler sugere que o principal motivo para o crescimento das firmas pode ser atribuído às economias de escala e escopo, fortemente ligadas à redução dos custos de transação (CARDOSO; BOMTEMPO; PINTO Jr., 2006, p. 70).

Para Peters e Waterman (1982 apud ALMEIDA; MACHADO NETO; GIRALDI, 2006, p. 20), o sucesso de uma empresa depende da estratégia e da estrutura, mas também dos sistemas, estilo, habilidades, pessoas e valores compartilhados. A estrutura (modo básico pelo qual as diferentes atividades da empresa são organizadas) é a primeira alavanca; a liderança (necessidade de estabelecer um estilo efetivo e também o pessoal necessário e habilitado para executar a estratégia) é a segunda alavanca; a cultura (valores compartilhado que criam as normas de comportamento individual e o tom da organização) é a terceira.

Almeida et al. (2006) ressaltam que a estratégia e a estrutura são formadas de maneira interdependente, cada uma influenciando e sendo influenciada pela outra, e que ambas são condicionadas pelo ambiente.

Para Souza e Clemente (2007, p. 4), os cenários socioeconômicos abrem oportunidades para a formulação e a implementação de novas estratégias, implicando novas decisões de investimentos, ou seja, a estrutura se modifica para viabilizar a estratégia. Contudo, as estratégias e, por conseguinte, as decisões de investimentos são limitadas pelas oportunidades ou portfólios de projetos viáveis disponíveis. A estrutura atual, as expectativas de retorno e de riscos, a capacidade de geração e a captação de recursos também atuam como fatores limitantes na seleção de projetos de investimentos e, por conseguinte, no conjunto de opções estratégicas. Assim, a estrutura também atua como condicionante na composição do conjunto de opções estratégicas. 


\section{A ESTRATÉGIA E A GESTÃO DE CUSTOS}

A vantagem competitiva não pode ser entendida olhando-se para a empresa como um todo. Ela provém das muitas atividades distintas executadas por uma empresa ao projetar, produzir, comercializar, entregar e prestar assistência ao seu produto. Cada uma dessas atividades pode contribuir para a posição relativa de custo de uma empresa e criar uma base para a diferenciação. A cadeia de valor desagrega uma empresa em suas atividades estrategicamente relevantes para compreender o comportamento dos custos e as fontes existentes e potenciais de diferenciação (PORTER, 1985, p. 33).

Segundo Ansoff (1991, p. 52), para garantir a sua sobrevivência e o seu sucesso, a empresa precisa otimizar a eficiência de seu processo de conversão de recursos, isto é, o retorno para a empresa, ou lucro, deve ser otimizado em relação aos recursos empregados para gerá-lo, isto é, faz-se necessária uma boa gestão da produção. É necessário buscar a eficiência na transformação de recursos em produtos, baixando o custo de cada elemento da cadeia de valor. $\mathrm{Na}$ teoria econômica clássica, considerando-se o mercado perfeito, sem limitações de demanda, pode-se caracterizar a função que exprime e maximiza o lucro possível de ser obtido. O lucro máximo é alcançado num nível de faturamento no qual os custos marginais dos bens produzidos são exatamente iguais às receitas marginais. A suposição implícita é a de que os recursos empregados na firma podem ser ajustados livremente e reduzidos ou elevados na quantidade exata para gerar o nível ótimo de faturamento, o que sabidamente não é uma verdade.

A partir da década de 1960, a maioria dos estrategistas lançou mão de algum tipo de análise de custos para avaliar o posicionamento competitivo. Deu-se maior ênfase à desagregação do negócio em seus componentes, bem como a avaliação de como os custos poderiam ser rateados entre negócios da mesma atividade. A partir desse movimento, os estrategistas "enriqueceram grandemente o seu cardápio de direcionadores de custos (cost drivers), expandindo-o para além da simples experiência" (GHEMAWAT, 2000). Essa ainda era uma visão voltada à produção, sem dúvida um passo adiante do método clássico do Custeio por Absorção, mas ainda direcionada para dentro da organização, o que desconsiderava o poder soberano do mercado sobre a lucratividade da empresa, ou seja, era uma visão míope, restrita e inadequada para lidar com as pressões ambientais do mercado competitivo. Essa sofisticação foi seguida, segundo Ghemawat (2000), tardiamente, pela maior atenção dada aos clientes, o que levou à reconsideração da posição estratégica de baixo custo, que era considerada como a mais adequada. $\mathrm{O}$ foco da atenção no cliente, voltando-se para fora da organização, mostrou que era preferível uma diferenciação do produto, gerando uma disposição a pagar um preço mais elevado por ele, porém, ainda assim, dando chance a uma redução de custos.

Para Yip (1996, p. 744) a redução de custos pode ser aplicada das seguintes maneiras: aumentar os benefícios de economias de escala; explorar o fator mais baixo de custos pela transferência de produção ou de outras atividades para locais de custo baixo; explorar a flexibilidade (transferir a produção de um local para outro, onde há outras sedes de fábrica, em curto prazo para tirar proveito de custos mais baixos em um determinado momento) e realçar o poder de negociação (com fornecedores, trabalhadores e governo). A economia de escala, o aprendizado e a experiência, a eficiência nas fontes de suprimento, a logística favorável, as diferenças de custos e de habilidades do local onde a empresa está implantada e os custos de desenvolvimento do produto são os principais impulsionadores de custos (cost drivers) que afetam a economia do negócio. Pode-se perceber, na visão de Yip, que a economia de escala é apenas um dos fatores que interferem nos custos do processo produtivo. Logística favorável, transferência para locais de baixo custo e outras estratégias interferem nos custos fixos e indiretos e, por consequência, no posicionamento competitivo desejado. Percebe-se aqui um alinhamento entre Yip a posição sustentada por Chandler em Estratégia e estrutura (2000) e em Escala e escopo (1990).

Em Shank e Govindarajan (1997), vê-se que "a gestão estratégica de custos pode representar um modo tão diferente de pensamento sobre a contabilidade gerencial que acabará representando uma mudança de paradigma". Assim sendo, o novo conceito de gestão estratégica de custos mistura os conceitos e os métodos de análise financeira com temas de gestão estratégica: análise da cadeia de valor, análise do posicionamento estratégico e análise dos direcionadores de custos (cost drivers). Reduzir o 
comportamento de custo a uma questão de custos fixos, variáveis ou mistos não explica os custos (nem as atividades desenvolvidas) de um modo que seja útil para o processo de geração e avaliação de estratégias. Segundo Souza e Clemente (2007), a gestão estratégica de custos redefine também o conceito de custos: os principais custos, na sua maioria, são consequências de estratégias anteriores que se materializam por meio de decisões de investimento. Esse conceito contemporâneo de custo resgata a importância da discussão da estrutura de custo que se instala com a estratégia selecionada.

Por muito tempo, o paradigma da busca por baixos custos em relação aos concorrentes foi a estratégia empregada para enfrentar a concorrência. Gradativamente, esse paradigma foi sendo substituído pelo melhoramento de outros aspectos que agregariam um diferencial ao produto, permitindo a cobrança de um valor extra. Assim, a avaliação de custo do produto não deve mais meramente abarcar o conceito de processo produtivo, ou seja, o custo de produção. Cada vez mais os custos adjacentes, a montante e a jusante do processo produtivo, tornam-se de maior importância para o mercado consumidor, ou seja, o custo total é compreendido como o custo produtivo em si, porém agregado a um custo de distribuição, que colocará o produto de forma mais eficiente no mercado; um custo de operação, gerado pela eficiência do produto na utilização dos recursos para o seu funcionamento; um custo de informação ao cliente, gerado por estruturas de marketing, publicidade, propaganda e outros; um custo de atendimento pós-venda, determinado pela instalação de serviços de atendimento ao consumidor, call-centers, ouvidorias, ombudsmen e similares e um custo de descarte, gerado pela desmobilização do produto ao fim de sua vida útil.

Deve-se manter à vista a preocupação de considerar o custo total do produto como um pacote formado pelo custo de aquisição, o custo de operação, o custo de distribuição, o custo de pós-venda e o custo de descarte, ou seja, por necessidades normativas, legais, institucionais e exigências do próprio mercado (incluindo as exigências ambientais como: produzir produtos ambientalmente seguros, utilizando materiais extraídos de forma adequada), conforme ilustrado na Figura 1. O processo de venda não se encerra com a colocação do produto no mercado; uma vez nas mãos do consumidor, o produto ainda pode gerar custos, decorrentes de falhas no processo

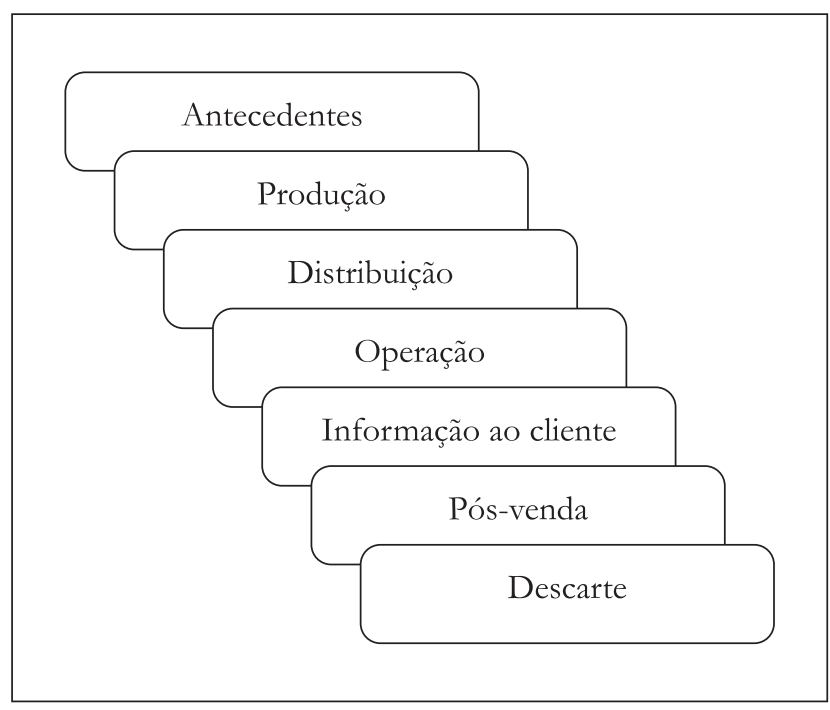

FIGURA 1 - Custos sob a ótica da gestão estratégica de custos

produtivo, levando a etapas de manutenção em prazo de garantia, horas de retrabalho, materiais sobressalentes e, eventualmente, substituição e reposição de unidades completas e acabadas.

Porter (1985) sugere a análise de custo e diferenciação por meio da cadeia de valor, enfatizando a necessidade de, cartesianamente, olhar o negócio como constituído de partes que interagem mutuamente, tornando a cadeia de valor conectada aos determinantes da posição de vantagem competitiva. Porter também afirmou que as empresas de sucesso, em geral, optaram por uma estratégia ou de baixo custo ou de diferenciação, ou seja, praticamente colocou ambas (as estratégias) como sendo mutuamente exclusivas - a menos que se utilize a estratégia de segmentação, na qual, ao atingir um determinado segmento de mercado, busca-se simultaneamente a vantagem da posição de baixo custo e da singularidade percebida pelo cliente. Essas estratégias genéricas, segundo Ghemawat (2000, p. 65), tinham apelo para os estrategistas por refletir a tensão criada pelo baixo custo e pela diferenciação, incluindo a percepção de que as estruturas, cultura corporativa e estilo de liderança necessários a uma empresa seriam radicalmente diferentes para outro tipo de empresa.

Torna-se aparente que as estratégias não são, de forma alguma, excludentes, ou seja, as empresas podem (e devem) descobrir maneiras de criar produtos de melhor qualidade (diferenciados) a custos 
mais baixos. Porter (1985) afirmou que tais empresas são raras, normalmente baseadas em vantagens operacionais que são facilmente copiadas.

Ghemawat (2000, p. 66) coloca ainda que, apesar da determinação da direção da empresa em levar a operação a extremos ou de baixo custo ou de elevada diferenciação, as condições ambientais podem levar o ponto de operação novamente de volta ao centro. Do ponto de vista Keynesiano, o cliente é que vai determinar o ponto de operação da empresa, frequentemente desejando um produto com um determinado nível de diferenciação a um custo acessível, garantindo o seu grau de satisfação.

A redução de custo acontece por mudanças no processo ou no projeto. Por outro lado, há que se tomar cuidado com a natureza das mudanças efetuadas; toda mudança deve trazer algum tipo de resultado positivo, pois a mudança que não provoca uma melhoria leva a um aumento de custos. Uma forma de gestão bastante empregada para atingir os objetivos de redução de custos dos processos é o kaizen, que tem como conceito básico o saber distinguir o que é valor acrescentado daquilo que não acrescenta valor (desperdício). Quando essa percepção se torna clara e evidente, pode-se dizer que se está praticando o kaizen, ou melhoria contínua. Dessa forma, a aplicação de ferramentas kaizen objetiva a melhoria de rentabilidade por meio da satisfação dos clientes no que se refere à qualidade, ao custo e aos serviços, melhorando a cadeia de valor.

Pode-se entender, então, a posição de Shank e Govindarajan (1997) como um ciclo de refinamento contínuo, ou seja, as estratégias determinam novos processos para a firma que, por sua vez, tem seus custos e ganhos refletidos nos demonstrativos contábeis, os quais gerarão as informações necessárias para que os estrategistas verifiquem a adequação das implementações às estratégias pretendidas. Mutatis mutandis, também percebe-se aqui a assertiva de Chandler - a estrutura segue a estratégia - na posição defendida por Shank e Govindarajan.

Por certo, se uma empresa conseguir gerenciar seus custos sob a ótica da competitividade, conquistará uma vantagem competitiva, pois tal procedimento não é trivial e demanda um esforço que, adotados os meios tradicionais de custeio, torna-se árduo, oneroso e complexo, dificultando a sua viabilidade.

\section{A GESTÃO DE CUSTOS E OS MÉTODOS DE CUSTEIO}

Os sistemas de custeio, tendo sido concebidos e desenvolvidos para fornecerem informações aos decisores segundo certa filosofia administrativa, foram, sem exceção, inicialmente satisfatórios. Entretanto, as mudanças tecnológicas, a adoção de novos paradigmas de administração, bem como as mudanças no mundo dos negócios, especialmente as relacionadas à competição, seja por recursos produtivos, seja por clientes, apresentaram ao longo do tempo requisitos novos de informação, que conduziram ao surgimento de novos sistemas de custeio devido à crescente insatisfação com os sistemas anteriores. Diante disso, é possível prever que as transformações da economia, em nível mundial, neste final de milênio, trarão substanciais mudanças para a prática de custeio nas empresas, em particular no que se refere aos custos da qualidade e do meio ambiente (SOUZA; CLEMENTE, 1998, p. 142).

Para fins de uma melhor gestão de custos nas organizações as contabilidades financeira e gerencial fazem-se necessárias: a financeira, do ponto de vista legal, e a gerencial, para gerar maior confiança nas tomadas de decisões estratégicas da empresa. A contabilidade financeira é parte do sistema que provê informações para usuários externos à organização, é orientada pelos princípios contábeis geralmente aceitos (HANSEN; MOWEN, 1997) e sofre controle principalmente normativo (FASB local, órgãos governamentais e legislação societária), enquanto que a contabilidade gerencial pode ser influenciada pelo estilo de seus gestores e por outras empresas do mercado (FREZAT'TI; AGUIAR; GUERREIRO, 2006, p. 15). A contabilidade financeira e a gerencial utilizam-se de alguns métodos de custeio para o controle e tomada de decisões, e, dentre eles, os mais utilizados pelas empresas brasileiras são: o custeio direto ou variável, o custeio por absorção e o custeio por atividades $(\mathrm{ABC})$.

O Método de Custeio Direto tem as seguintes características, conforme Souza e Clemente (1998): origem gerencial; orientado para as funções financeiras e de marketing; vendas como elemento gerador de riqueza; só os custos variáveis são imputados aos produtos; os custos fixos pertencem à 
estrutura; margem de contribuição unitária como parâmetro de análise e ênfase na análise da relação custo-volume-lucro e no mix ótimo de produção.

O Sistema de Custeio por Absorção ou Tradicional caracteriza-se, segundo Souza e Clemente (1998), por: origem no chão de fábrica; orientado para o controle da produção; produção como elemento gerador de riqueza; todos os custos são passíveis de serem imputados aos produtos; lucro unitário como parâmetro de análise e projetado para monitorar a produção em termos de volume, tempo e custo.

A complexidade dos processos, o aumento substancial da variedade de produtos produzidos por uma única empresa e o surgimento de uma economia globalizada cada vez mais competitiva evidenciou a necessidade de um novo sistema de informações de gestão de custos que melhor refletisse o comportamento dos custos, ou seja, a forma como os recursos eram consumidos dentro da empresa. No fim dos anos 1980 a nova abordagem de gerenciamento de custos já estava desenvolvida; neste período é que Robert Kaplan e Robin Cooper divulgam o Activity-Based Costing (COOPER; KAPLAN, 1988). Nesse artigo, os autores estabelecem que os administradores de companhias que vendem vários produtos tomavam decisões estratégicas a respeito de precificação e de mix de produtos com informações distorcidas de custo (devido ao uso dos sistemas de custeio disponíveis na época), normalmente só reconhecendo o problema quando a competitividade e a lucratividade já se houvessem deteriorado. Daí surgiu a proposta do Activity-Based Costing (ABC), estabelecendo que esse sistema poderia conviver com o sistema atual de custeio e auxiliar no gerenciamento estratégico da empresa.

OSistema ABC possibilita intervenções nos processos, na composição dos custos e na análise de variações possíveis e, para Souza e Clemente (1998), apresenta as seguintes características: orientado para o processo; aplicável a toda a cadeia de valor; as atividades consomem recursos e os produtos consomem atividades; identifica as atividades que agregam valor aos produtos; rateia os custos indiretos com critérios multidimensionais; identifica responsabilidade pelas atividades que mais consomem recursos.

Quanto maior a organização e mais diversa a gama de produtos ou serviços, mais complicada a aplicação do Sistema $A B C$, tendo em vista a complexidade das informações e dos cálculos para os custos. Com o avanço da tecnologia da informação aplicada para o Sistema de Informação Contábil, essa árdua tarefa torna-se possível, apesar da complexidade normativa decorrente de sua implementação (como, por exemplo, o correto apontamento e apropriação de horas de trabalho) ser um fator fortemente negativo para o seu sucesso.

Cabe ressaltar que, segundo Grasso (2005), o custeio $\mathrm{ABC}$ é adequado para empresas que consomem recursos em longo prazo, pois todos eles são apropriados ao custo, até mesmo a capacidade ociosa. Assim, não contribuem para melhoria de desempenho de pequenas empresas. Também, no $\mathrm{ABC}$ é difícil identificar que atividades contribuem para a satisfação dos clientes internos e externos. $\mathrm{O}$ mesmo autor comenta que os gerentes das empresas acreditam que o custo para desenvolver e manter o $\mathrm{ABC}$ excede os benefícios gerados.

A principal crítica ao $\mathrm{ABC}$ realizada por Grasso, com relação ao uso do mesmo em empresas de produção enxuta, pois as mesmas preferem uma visão de custeio incremental ao ABC.

\section{METODOLOGIA}

Trata-se de uma pesquisa teórico-empírica quanto à sua natureza; descritiva, quanto ao seu objetivo; qualitativa, quanto à abordagem do problema; bibliográfica e de estudo de caso, no que se refere aos procedimentos técnicos. A abordagem metodológica proposta consiste basicamente em, a partir de um referencial teórico básico (CHANDLER, 2000), mostrar que a busca por vantagens competitivas se dá por meio da provocação de desequilíbrios no processo de competição seguido de ajustes na estrutura até que essa vantagem competitiva seja ameaçada ou erodida, reiniciando um novo ciclo.

\section{O ESTUDO DE CASO}

O estudo de caso foi conduzido em uma indústria de tijolos e artefatos de refratários situada na região Sul do Brasil que, por razões de privacidade, prefere não se identificar. Doravante, será referida como IRSB (Indústria de Refratários do Sul do Brasil). A empresa tem em seus registros documentos como sendo a mais antiga a fabricar tijolos de alta sílica no Brasil e na América do Sul. Em seus mais de 75 anos de existência possui um nome consolidado no 
mercado nacional. Possui grande diversificação de produtos, sua linha de produção está voltada para tijolos refratários formados (prensados e cozidos), e também de não formados (que não precisam ser prensados e cozidos), argamassas, concretos, massas de recuperação, chamotes e outros afins. Atua na distribuição de materiais para isolamentos térmicos (fibras cerâmicas, lã de rocha, lã de vidro, vermiculita, tijolos isolantes). Em seus nichos de negócios destacam-se os ramos de fundição de ferrosos e não ferrosos, agronegócio, construção civil, celulose e outros que tenham fontes de geração de calor. Neste estudo são analisados os custos de produção de duas composições de massas (silicosa e silico-aluminosa) integrantes do portfólio da empresa.

\section{A ESTRUTURA CONDICIONANDO A ESTRATÉGIA}

A empresa é detentora do direito de lavra de minas de argila refratária silicosa e de quartzito e, no passado, trabalhava exclusivamente com a extração ea transformação de matérias-primas de minas próprias. Tais matérias-primas são indispensáveis para a fabricação de tijolos do tipo ácidos refratários, utilizados para o revestimento de fornos de fundições dos tipos "Cubilot, Cadinhos, Rotativos e outros". Esses tijolos formados de alta sílica dominaram o revestimento dos fornos Cubilot (alto-forno abastecido a carvão coque e projetados para grandes volumes de produção de metal fundido, seguindo o paradigma da produção em massa: produção em grandes lotes para diluir os custo fixos) nas décadas de 1930 até 1990.

\section{A OPORTUNIDADE, A ESTRATÉGIA E AS DECISÕES DE INVESTIMENTOS}

Com a modernização e a necessidade de otimização de custos, muitas empresas desativaram os fornos Cubilot e instalaram fornos à indução (elétricos), que são equipamentos intermitentes de menor capacidade de produção e se adéquam aos volumes de produção de empresas de médio porte. Dessa forma, houve a diminuição de demanda por tijolos refratários formados e a troca por uma massa refratária não formada aplicada através de socagem com marteletes pneumáticos que moldam a forma monolítica dos fornos à indução.
A partir dos anos 90 o agronegócio investiu fortemente em unidades de beneficiamento e secagem de grãos e passaram a utilizar tijolos refratários com maior resistência mecânica para o revestimento de suas fornalhas dos secadores. Tendo em vista essa oportunidade que despontava, a IRSB lançou uma linha de tijolos silico-aluminosos (tijolos com resistência mecânica elevada) para atender a esse segmento. Assim, a empresa direcionou esforços para diversificar sua linha de produtos e ampliar seus nichos de negócios, investindo maciçamente em tecnologia de materiais e melhoria de equipamentos para se obter maior produção e, em consequência, redução de custos.

O tijolo refratário silicoso é um tijolo ácido, com resistência mecânica média e sensível ao choque térmico, altamente resistente ao ataque de gases ácidos que são liberados no momento do derretimento do ferro. Sua escória não proporciona inclusão na liga do ferro, sua temperatura máxima de trabalho está entre $1.650^{\circ} \mathrm{C}$ e $1.700^{\circ} \mathrm{C}$. Tal material é utilizado em revestimento de fornos de fundições, panelas de vazamentos e de transportes de metais fundidos. O tijolo refratário sílico-aluminoso é um tijolo básico, com alta resistência mecânica e resistente ao choque térmico, tem baixa resistência ao ataque de gases ácidos gerados no momento de derretimento de ferro, sua refratariedade é baixa, e sua escória inclui-se na liga do ferro fundido. A temperatura de trabalho fica entre $1.300^{\circ} \mathrm{Ca} 1.450^{\circ} \mathrm{C}$. É mais indicado para o revestimento de fornalhas em geral, churrasqueiras e lareiras, mas são também muito cobiçados pela construção civil para confecção de paredes e revestimento de fachadas de casas e prédios. Dessa forma, os tijolos sílico-aluminosos não se prestam ao uso em fornos de fundição. Além disso, esses fornos necessitam de resistência a altíssimas temperaturas, sendo essa uma propriedade dos tijolos de sílica. Por outro lado, as fornalhas e secadoras agro industriais não atingem temperatura tão elevada quanto os altos-fornos e necessitam de material com resistência mecânica para suportar os impactos de carregamento e descarregamento do forno. Assim, do principal produto, que era os tijolos refratários silicosos para os fornos de fundição, que respondiam por $95 \%$ da produção, passou-se a produzir tijolos refratários sílico-aluminosos para fornalhas, caldeiras e secadoras de grãos.

Os tijolos sílico-aluminosos, com 30\% de óxido de alumínio $\left(\mathrm{Al}_{2} \mathrm{O}_{3}\right)$ ou alumina, passaram a 
ser o carro-chefe da empresa, com mais de $79 \%$ da produção mensal, e atualmente custam cerca de um quarto do valor do tijolo produzido pela concorrência, com $42 \%$ de óxido de alumínio na sua composição. São tijolos de excelente qualidade para o uso em fornalhas em geral e o custo baixo para produzir esse produto ocorre em função da matéria-prima, que já contém os elementos necessários para o fabrico de refratários com teores característicos de sua composição geológica in natura, não havendo necessidade de adicionar elementos químicos.

Os tijolos silico-aluminosos de $42 \%$ de alumina são tijolos mais nobres e indicados para trabalhos que exijam temperaturas de até $1.450^{\circ} \mathrm{C}$, têm maior resistência mecânica e ao ataque de gases. São utilizados em fornalhas em geral, fornos de fundição de chumbo e outros. O teor de $42 \%$ de alumina não é característico da matéria-prima in natura e sim de uma complementação de outros materiais e química, por isso a diferença de preço é significativa tanto na produção quanto para a venda.

Investir no novo nicho de mercado foi uma estratégia adotada para manter-se no mesmo. Para enfrentar a concorrência de baixos custos a IRSB optou em fabricar um produto buscando a melhor relação entre qualidade e custo, adotando um compromisso com a melhor resistência mecânica e a melhor resistência à temperatura, por isso optando pelos tijolos de 30\% de alumina. Gradativamente foi investindo em equipamentos para obter maior produção, visto que o que produz é absorvido pelo mercado interno e a meta futura é atingir o mercado externo (exportação). Atualmente, o limite máximo de produção não ultrapassa 800 toneladas ao mês, porém a expansão já está em andamento.

\section{O SISTEMA DE INFORMAÇÕES DE CUSTOS}

A análise dos custos, por questão de acesso aos dados, ficou restrita a dois produtos: o tijolo refratário sílico-aluminoso com $30 \%$ de alumina $\left(\mathrm{Al}_{2} \mathrm{O}_{3}\right)$ e o tijolo refratário silicoso até $95 \%$ de sílica (dióxido de silício - $\mathrm{SiO}_{2}$ ). Os custos abrangem a matéria-prima, beneficiamento, insumos, mão de obra, energia elétrica, cozimento, embalagens, movimentações, custos administrativos e o tempo para transformá-la em produto acabado. Por trabalhar com centros de custos e também por considerar os custos administrativos na composição dos custos, o método de custeio utilizado se aproxima da variante RKW do Custeio por Absorção (SOUZA; CLEMENTE, 2007).

O tijolo refratário silicoso apresenta uma vantagem competitiva para a empresa, visto que a mesma é detentora da matéria-prima, porém também gera um custo fixo para manter as minas de argila e arenitos. Para mantê-las em funcionamento é necessário possuir profissionais técnicos (engenheiro de minas, geólogo), registro no Departamento Nacional de Produção Mineral (DNPM), além da obrigatoriedade de recomporáreas degradadas com reposição de vegetação nativa, também ficando a cargo da empresa todo o custo de equipamentos para a extração e a logística de transporte.

Já o tijolo silico-aluminoso é produzido com matéria-prima adquirida de terceiros; dessa forma, não gera custos fixos, tendo em vista que a aquisição ocorre em função da demanda, porém condiciona à dependência de recursos externos à organização.

Relativo à utilização do fator trabalho na composição dos custos, é importante ressaltar que essa organização apresenta uma peculiaridade: um funcionário pode trabalhar em todos os setores, dependendo da necessidade de produção do momento. Assim sendo, os custos de mão de obra direta e indireta são computados de forma a que todos os diferentes valores de salários pagos aos funcionários da empresa são somados e divididos pelo tempo total de trabalho mensal (220h), definindo-se então o valor do homem-hora. Tendo-se em vista tal valor, dimensiona-se o tempo utilizado para produzir a tonelada do produto, resultando no valor total de mão de obra por tonelada. Esse sistema só funciona porque a equipe trabalha com responsabilidade e espírito de cooperativismo; para tanto, os funcionários são generalistas e a empresa paga salários acima do mercado.

O consumo de energia elétrica para a produção da tonelada de produto é calculado com base em uma estimativa do valor-hora, apropriando-se posteriormente ao processo produtivo com base em sua utilização. O consumo de lenha e de óleo de xisto (combustíveis para os fornos) é calculado diretamente por tonelada do produto, pela característica de sua utilização no funcionamento de fornos de queima, sendo que o prazo de queima é distinto para cada tipo de produto (de três a sete dias). 
O custo da manutenção e do desgaste dos equipamentos dilui-se na tonelada do produto, sendo apropriado na margem de perda dos produtos.

Ao finalizar o processo produtivo, cada lote de tijolos é colocado em pallets e plastificado. Os pallets contêm entre 504 a 540 peças, compondo $1 \mathrm{~m}^{3}$ (conforme recomendação da ABNT). O transporte do produto é terceirizado. Assim, vende-se pelo preço FOB e compra-se pelo valor FOB. A representatividade nas vendas é apresentada na Tabela 1.

TABELA 1 - Volume de produção e representatividade no volume de vendas

\begin{tabular}{|c|c|c|c|c|c|}
\hline & \multirow[b]{3}{*}{$\begin{array}{r}\text { Volume de Produção } \\
\text { (ton./mês) }\end{array}$} & \multicolumn{4}{|c|}{ Representatividade no volume de vendas } \\
\hline & & \multicolumn{2}{|c|}{ Tijolos refratários } & \multicolumn{2}{|c|}{ Materiais não formados } \\
\hline & & silicosos & sílico-aluminosos & silicosos & sílico-aluminosos \\
\hline $\begin{array}{l}\text { Antes de } \\
1992\end{array}$ & 200 & $95 \%$ & $0 \%$ & $5 \%$ & $0 \%$ \\
\hline $\begin{array}{l}\text { Depois de } \\
1992\end{array}$ & 800 & $3,33 \%$ & $79,61 \%$ & $1,95 \%$ & $15,11 \%$ \\
\hline
\end{tabular}

Cumpre notar que não é apropriado aos custos do produto o patrimônio em imóveis, veículos, maquinário e equipamentos; também a depreciação não é computada, pois o maquinário da empresa (britadores, moinhos, prensas, veículos, instalações e outros) tem uma vida econômica longa e já passaram da vida útil para efeito de depreciação. A manutenção é feita in loco e o custo associado com o "consumo desses recursos" está diluído na mão de obra, em função do custo baixo de manutenção.
Embora o produto formado (tijolos) seja o principal, o produto não formado (massas, argilas, argamassas, concretos e outros) repassa à empresa uma margem de lucro maior. Também os produtos revendidos representam margem maior de lucro, pois acabam entrando como componentes secundários que compõem um pacote para montagem de fornos, fornalhas, secadoras, lareiras e churrasqueiras. A representatividade dos diferentes produtos é apresentada na Tabela 2.

TABELA 2 - Representatividade dos produtos no faturamento médio mensal da empresa IRSB em 2007

\begin{tabular}{lcccc}
\hline & \multicolumn{3}{c}{ Representatividade no volume de vendas } \\
\cline { 2 - 4 } & \multicolumn{2}{c}{ Tijolos refratários } & \multicolumn{2}{c}{ Materiais não formados } \\
\cline { 2 - 4 } & silicosos & sílico-aluminosos & silicosos & sílico-aluminosos \\
\hline Quantidade vendida (ton./mês) & 26,40 & 636,88 & 15,60 & 120,88 \\
Preço de venda (R\$/ton.) & 950,00 & 323,53 & 750,00 & $1.100,00$ \\
Faturamento médio (R\$/mês) & 25.080 & 206.050 & 11.700 & 132.968 \\
Representatividade do faturamento & $6,67 \%$ & $54,83 \%$ & $3,11 \%$ & $35,38 \%$ \\
\hline
\end{tabular}


Percebe-se que a organização cresceu quando buscou uma estratégia de diversificação e investiu na contratação de especialistas que verificaram o material e buscaram melhorias de processos agregando valor aos produtos. Apesar dos esforços, o retorno do investimento ainda é baixo e não permite à empresa uma grande expansão.

\section{A GESTÃO ESTRATÉGICA DOS CUSTOS E PRECIFICAÇÃO}

Uma análise do processo produtivo e de sua apropriação em termos de custeio, com o apoio do pessoal interno da empresa, revela que existe uma grande preocupação com a identificação dos elementos que compõem o custo de cada produto, de tal forma que eles possam ter sempre uma noção de competitividade e de formação de preço adequadas para cada elemento de seu portfólio. Identificou-se que todos os custos de mão de obra são alocados em um pool, dividindo-se o custo total dessa força de trabalho (incluindo impostos e demais encargos) pelo número de horas trabalhadas, obtendo-se, assim, um valor base para o homem-hora.

Observa-se que houve a agregação do que seria um custo de mão de obra produtiva (envolvida diretamente no processo produtivo) com o custo da mão de obra administrativa (toda aquela não envolvida diretamente com o processo produtivo), devido ao estabelecimento da estrutura e funcionamento matricial, no qual diferentes empregados se realocam matricialmente de forma a sustentar o processo produtivo da melhor forma possível em todas as condições de operação. Essa forma de alocação, direcionada pelo tempo, é feita em conformidade com o pensamento de Kaplan e Anderson (2004), que preconizam a utilização do tempo em detrimento de outros direcionadores de custos.

Em uma estrutura tradicional que diferencie claramente o processo produtivo do processo administrativo (ou não produtivo), ao utilizar o tempo do processo produtivo como direcionador de custos para as atividades, é feita uma pressuposição implícita de que a proporção de tempo gasto no processo não produtivo é igual à proporção de tempo gasto no processo produtivo para cada produto produzido, o que nem sempre é verdade (um produto que tenha menor tempo produtivo pode ter mais tempo de atividade administrativa envolvida). Assim sendo, conforme a situação torna-se necessário o envolvimento de consultores que apontem adequadamente o total de horas empregado em cada um dos processos.

O exame da planilha de custos mostrou que apenas a matéria-prima, combustíveis (para a queima nos fornos) e embalagem (filme PVC, pallet de madeira e gás para fundir o filme) são diretamente atribuídas aos produtos. O restante, incluindo máquinas, energia elétrica, combustível para empilhadeira e movimentadores diversos é calculado e apropriado em cada produto por meio do rateio de tempo de produção, em conformidade com Kaplan e Anderson (2004), o que permite inferir que o método de custeio gerencial que a empresa adota aproxima-se bastante do $\mathrm{ABC}$ com direcionador tempo (time-driven $\mathrm{ABC}$ ). Ressalta-se que a depreciação não é computada, uma vez que os ativos imobilizados já ultrapassaram o tempo de vida útil para tal procedimento contábil e a manutenção dos mesmos é realizada internamente, colocando-a nos custos do homem-hora.

Enquanto atualmente o custeio é um misto entre o custeio direto e o custeio ABC com direcionador tempo, o custeio anterior ao ano de 1992 era feito por absorção. No passado, trabalhavam somente com matéria-prima própria (não dependiam do mercado), assim, agregava-se a extração da matéria-prima aos custos normais. Todavia, o valor do material extraído, em função de ser mina própria, não era necessariamente mensurado com o preço real de mercado, ou seja, não levava em conta o preço da argila e do arenito se fossem comprados de terceiros. Hoje, com os recursos de informação aos quais se tem acesso, torna-se fácil mensurar o custo de materiais, conhece-se exatamente quanto custa cada item e quanto é gasto para produzir. A partir desse ponto a empresa obteve ganhos, mesmo trabalhando com margens de lucro pequenas, e sabe que está auferindo lucro em função do aumento de produção, diversificação e revendas.

Percebeu-se também que a empresa utiliza, ao menos intuitivamente, os conceitos de produção enxuta, o que a leva a buscar novas formas de gestão de custos.

Para sobreviver em um ambiente competitivo, a IRSB percebeu que não deveria formar estoque nem de produtos acabados, nem de matéria-prima. Assim sendo, entrou num sistema de produção puxada, daí decorrendo um sistema de produção entrega on-time e processo just-in-time (cliente faz o pedido, produzem-se as unidades necessárias e 
contrata-se um frete terceirizado para entregar). A utilização desse sistema resultou em satisfação do cliente, minimização do tempo dock-to-dock (apesar de ainda apresentar características de retrabalho, contrariando o princípio do first time through), maior giro do estoque de matéria-prima e, mais importante, aumento no volume de vendas.

\section{AS INFORMAÇÕES DE CUSTOS E A REORIENTAÇÃO DA ESTRATÉGIA}

Ao analisar as informações obtidas com a gestão de custos, a IRSB verificou que não teria condições de concorrer com uma estratégia de baixo custo com o mesmo produto que o concorrente. A maior concorrência para a empresa avaliada vem dos fabricantes da própria região Sul do Brasil, que produzem em grandes escalas e têm matérias-primas com custo baixo e, em consequência, preços de vendas atrativos. Porém, a IRSB tem um produto similar, com um custo um pouco mais elevado, que é compensado pela qualidade.

A empresa tem agido no sentido de atuar duplamente: melhorar a percepção do consumidor a respeito da utilidade do produto com o consequente aumento da disposição a pagar e reduzir os custos, controlando e aprimorando o processo produtivo. A concorrência acirrada está exigindo o remodelamento do negócio como estratégia competitiva, por causa das pressões enfrentadas no segmento de baixo custo e no de valor elevado. Hoje a empresa opera em um nicho restrito, buscando eficiência no processo produtivo, com a ressalva de que todos os autores aqui estudados colocam que esse tipo de estratégia não vai muito longe, pois se move exclusivamente ao longo do eixo de volume de produção, além de ser perfeitamente imitável.

O movimento estratégico que está sendo tomado atualmente é rever a estratégia de baixo custo, buscar diferenciação e focar maior atenção nas necessidades dos clientes. $O$ foco no cliente com diferenciação de produto permite preços mais elevados. Essa estratégia da empresa a está levando para um degrau acima na cadeia de valor. Com a análise da cadeia de valor foi possível descobrir onde o valor pode ser aumentado na percepção do cliente, mantendo-se a disposição a pagar, corroborando a concepção de Shank e Govindarajan (1997). Assim, a IRSB está oferecendo ao mercado produtos acabados que usam os seus refratários como componentes, agregando outros componentes externos e operando como sistemistas, fornecendo, por exemplo, kits para a montagem de secadores de grãos. Dessa forma, busca-se sair do nicho restrito em que opera hoje, ao mesmo tempo em que procura novas fronteiras geográficas para a colocação de seus produtos, indo ao encontro das necessidades das novas fronteiras agrícolas do Brasil.

\section{CONCLUSÕES}

O objetivo deste artigo era mostrar, por meio de um estudo de caso, que a assertiva de Alfred Dupont Chandler - a estrutura segue a estratégia (CHANDLER, 2000) - é abrangente o suficiente para incluir o sistema de informações de custos. $O$ referencial teórico utilizado (MINTZBERG, 1991; BESANKO, 1999; PEARCE II; ROBINSON Jr., 2000 apud ALMEIDA et al., 2006; SOUZA; CLEMENTE, 2007) corrobora a assertiva de Chandler, mas ressalta que estrutura e estratégia se relacionam de forma dinâmica, no sentido de que também a estrutura atua como condicionante das escolhas estratégicas.

$\mathrm{Na}$ empresa estudada observou-se que a estrutura (ser detentora do direito de lavra de minas de argila refratária silicosa e de quartzito) e o tipo de concorrência - oligopólio homogêneo - condicionaram a estratégia competitiva: alto volume de produção e custos de produção baixos e preços competitivos. As mudanças das forças competitivas dos anos 90, quer por inovação tecnológica, quer por reorientações das características da demanda, induziram a empresa a buscar diversificação em sua linha de produtos, implicando decisões de investimentos (novos processos e novos canais de distribuição) que resultaram em uma nova estrutura de custos. A preocupação com custos ambientais elegais, adjacentes ao processo produtivo dos tijolos silicosos que são fabricados com matéria-prima de mina própria ajudou a definir o movimento estratégico em direção aos tijolos sílico-aluminosos.

O foco no core business e o uso de sistemas de informações de custos (Direto e ABC) ajustados para produzir informações mais realísticas sobre custos de produção e margem de contribuição permitiram à IRSB reorientar a estratégia de diversificação com baixo custo para uma estratégia de diferenciação 
(oligopólio diferenciado), centrando-se nos produtos de maior margem.

A IRSB, que trabalhava, antes de 1992, com venda de lotes grandes da produção para poucos clientes, após 1992 passou a trabalhar com venda de lotes pequenos para vários clientes, estratégia essa que criou o ambiente adequado para o uso do custeio quase-ABC. A empresa estudada trabalhava com estratégias genéricas para um segmento em particular (altos-fornos) e teve que optar por um novo enfoque, para um novo segmento (agronegócio), embora não tenha deixado de atender ao antigo. Dessa forma, optou pela estratégia de diferenciação para o novo nicho de mercado de forma a proporcionar um melhor atendimento das necessidades do público-alvo (agronegócio), fornecendo-lhe produtos formados e não formados, procurando encontrar maneiras de produzir produtos de melhor qualidade (diferenciados) a custos baixos, em relação à qualidade oferecida. Os produtos de mesmo padrão de qualidade tornam-se mais caros, porém os produtos mais baratos não mantêm o mesmo padrão. Outro diferencial estratégico está na localização, próxima ao mercado consumidor (regiões Sul, Sudeste e Centro-Oeste), proporcionando melhor logística de transporte. Assim, ainda mantém uma vantagem competitiva em relação aos concorrentes.

O estudo de caso na empresa IRSB também mostrou evidências desse alinhamento dinâmico interdependente entre estratégia e estrutura e que a chamada estrutura soft também se molda à estratégia, isto é, o sistema de informações de custos também se ajustou para atender à estratégia.

Quanto à assertiva de que "o papel da informação contábil dentro de uma empresa é o de facilitar o desenvolvimento e a implementação das estratégias gerenciais", explicitada por Shank e Govindarajan (1997, p. 115), faz-se necessário destacar que há dois conceitos para custos: um operacional, que o associa à expressão monetária dos recursos consumidos, e um estratégico, que o associa às consequências de decisões de investimentos anteriores, para materializar a estratégia selecionada. É esse segundo conceito que deve respaldar o processo de criação e seleção de estratégias (SOUZA; CLEMENTE, 2007, p. 14).

A empresa, ao utilizar um sistema de custos diferente do tradicional - historicamente a partir da mudança de foco de mercado (dos altos-fornos para os pequenos secadores) - pôde melhor monitorar a sua posição de mercado ao longo dos últimos 15 anos, e agir no sentido de evitar uma paralisia estratégica, tomando um rumo ascendente na cadeia de valor, mantendo-se num mercado bastante competitivo e exigente.

\section{REFERÊNCIAS}

ANSOFF, H. I. A nova estratégia empresarial. 2. ed. São Paulo: Atlas, 1991.

ALMEIDA, F. C.; MACHADO NETO, A.J.; GIRALDI, J. M. E. Estrutura e estratégia: evolução de paradigmas. Revista de Gestão USP, v. 13, n. 2, p. 15-26, 2006.

ARAÚJO Jr., J. T. Concorrência e potencial de acumulação: um comentário à tese de Eduardo Guimarães. Revista de Economia Política, v. 3, n. 1, p. 15-26, 1983.

BARNEY, J. Firm resources and sustained competitive advantage. Journal of Management, v. 17, n. 1, p. 99-120, 1991.

BESANKO, D. A economia da estratégia. 2. ed. Porto Alegre: Bookman, 1999.

CARDOSO, L. G; BOMTEMPO, J. V; PINTO Jr., H. Q. Compreendendo o crescimento das firmas: ferramentas de análise baseadas em Chandler e Penrose. O\&S, v. 13, n. 37, p. 69-85, 2006.

CHANDLER, A. D. Escala e escopo. 2. ed. Cambridge: MIT Press, 1990.

Strategy and structure: chapters in the history of the american industrial enterprise. 2nd ed. Cambridge: MIT Press, 2000.

COOPER, R.; KAPLAN, R. S. Measure costs right: make the right decisions. Harvard Business Review, v. 66, n. 5, p. 96-103, 1988.

DAY, G. S. Manutenção da vantagem competitiva: criação e sustentação das vantagens em ambientes competitivos dinâmicos. In:DAY, G. S.; REIBSTEIN, D. J.A dinâmica da estratégia competitiva. Rio de Janeiro: Campus, 1999. p. 293-316.

ENCICLOPÉDIA TEMÁTICA. Biografia de Alfred D. Chandler. Disponível em: <http://www.knoow.net/ cienceconempr/gestao/chandleralfred.htm $>$. Acesso em: 10 jul. 2009. 
FREZATTI, F; AGUIAR, A. B.; GUERREIRO, R. Diferenciações entre a contabilidade financeira e a contabilidade gerencial: pesquisa empírica a partir de pesquisadores de vários países. In: ENCONTRO DA ANPAD, 30., 2006, Salvador. Anais... Salvador: ANPAD, 2006.

GHEMAWAT, P. A estratégia e o cenário dos negócios: texto e casos. 2. ed. Porto Alegre: Bookman, 2000.

GRASSO, L. P. Are ABC and RCA accounting systems compatible with lean management? Management Assounting Quartely, v. 7, n. 1, p. 48-55, 2005.

GUIMARÃES, E. A. Acumulação e crescimento da firma. 2. ed. Rio de Janeiro: Zahar, 1982.

HANSEN, D. R.; MOWEN, M. M. Management accounting. 3rd ed. Cincinnati: South-Western College Pub., 1997.

KAPLAN, R. S.; ANDERSON, S. R. Time-driven activitybased costing. Harvard Business Review, v. 40, n. 4, p. 43-50, 2004.

PORTER, M. E. Vantagem competitiva. 2. ed. Rio de Janeiro: Campus, 1985.

Como as forças competitivas moldam a estratégia. In: MONTGOMERY, C.; PORTER, M. Estratégia: a busca da vantagem competitiva. Rio de Janeiro: Campus, 1998. p. 69-85.
SHANK, J. K.; GOVINDARAJAN, V. A revolução dos custos: como reinventare redefinir sua estratégia de custos para vencer em mercados crescentemente competitivos. 2. ed. Rio de Janeiro: Campus, 1997.

SOUZA, A.; CLEMENTE, A. Contextos, paradigmas e sistemas de custeio. In: CONGRESSO BRASILEIRO DE GESTÃO ESTRATÉGICA DE CUSTOS, 5., 1998, Fortaleza. Anais... Fortaleza: ABC, 1998. p. 141-156.

Gestão de custos: aplicações operacionais e estratégicas. 2. ed. São Paulo: Atlas, 2007.

YIP, G. S. Global strategy in a world of nations. In: MINTZBERG, H.; QUINN, J. The strategy process: concepts, contexts and cases. 3rd ed. New Jersey: PrenticeHall, 1996.
Recebido: 25/09/2009

Received: 09/25/2009

Aprovado: $21 / 11 / 2009$

Approved: $11 / 21 / 2009$ 